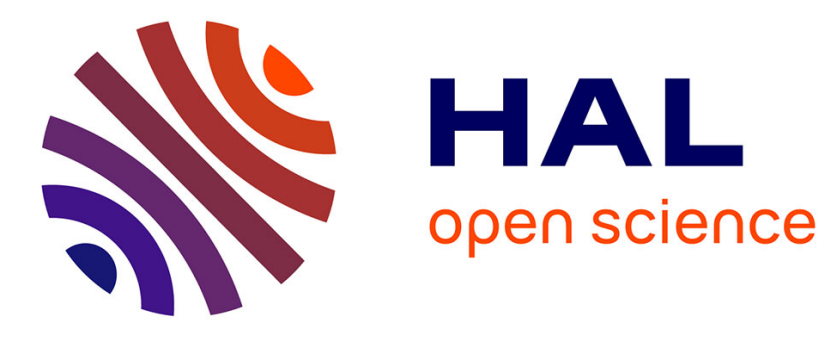

\title{
Surprising low diversity of the plant pathogen Phytophthora in Amazonian forests
}

Jean Legeay, Claude Husson, Benjamin Boudier, Eliane Louisanna, Christopher Baraloto, Heidy Schimann, Benoit Marçais, Marc Buée

\section{To cite this version:}

Jean Legeay, Claude Husson, Benjamin Boudier, Eliane Louisanna, Christopher Baraloto, et al.. Surprising low diversity of the plant pathogen Phytophthora in Amazonian forests. Environmental Microbiology, 2020, 22 (12), pp.5019-5032. 10.1111/1462-2920.15099 . hal-02736148

\section{HAL Id: hal-02736148 \\ https://hal.science/hal-02736148}

Submitted on 2 Jun 2020

HAL is a multi-disciplinary open access archive for the deposit and dissemination of scientific research documents, whether they are published or not. The documents may come from teaching and research institutions in France or abroad, or from public or private research centers.
L'archive ouverte pluridisciplinaire $\mathbf{H A L}$, est destinée au dépôt et à la diffusion de documents scientifiques de niveau recherche, publiés ou non, émanant des établissements d'enseignement et de recherche français ou étrangers, des laboratoires publics ou privés. 


\title{
Surprising low diversity of the plant pathogen Phytophthora in Amazonian forests
}

\author{
Jean Legeay ${ }^{1}$, Claude Husson ${ }^{1,2}$, Benjamin Boudier ${ }^{1}$, Eliane Louisanna ${ }^{3}$, Christopher \\ Baraloto $^{3,4}$, Heidy Schimann ${ }^{3}$, Benoît Marcais ${ }^{1 *}$, Marc Bué $e^{1^{*}}$ \\ 1 Université de Lorraine, Inra, UMR IAM - Interactions Arbres-Microorganismes -, F-54000 \\ Nancy, France \\ 2 Ministère de l'agriculture et de l'alimentation, DGAL, SDQPV, Département de la santé des \\ forêts, 75015, Paris, France \\ ${ }^{3}$ INRA, UMR EcoFoG - Ecology of Guiana Forests - (AgroParisTech, CNRS, CIRAD, \\ Université des Antilles, Université de Guyane), 97310, Kourou, France \\ ${ }^{4}$ International Center for Tropical Botany, Department of Biological Sciences, Florida \\ International University, Miami, Florida 33199, USA \\ * Corresponding authors: \\ marc.buee@inra.fr (M. Buée) - ORCID\# : 0000-0001-8614-3886 \\ benoit.marcais@inra.fr (B. Marcais) - ORCID\# : 0000-0002-8107-644X
}

\section{Abstract}

The genus Phytophthora represents a group of plant pathogens with broad global distribution. The majority of them causes collar and root-rot of diverse plant species. Little is known about Phytophthora communities in forest ecosystems, especially in Neotropical forests where natural enemies could maintain the huge plant diversity via negative density dependence. We characterized the diversity of soil-borne Phytophthora communities in the North French Guiana rainforest and investigated how they are structured by host identity and environmental factors. In this little-explored habitat, 250 soil cores were sampled from ten plots hosting ten different plant families across three forest environments (Terra Firme, Seasonally Flooded and White Sand). Phytophthora diversity was studied using baiting approach and metabarcoding (High Throughput Sequencing) on environmental DNA extracted from both soil samples and baiting-leaves. These three approaches revealed very similar communities, characterized by an unexpected low diversity of Phytophthora species, with the dominance of two cryptic species close to Phytophthora heveae. As expected, Phytophthora community composition of French Guiana rainforest was significantly impacted by the host plant family and environment. However, these plant pathogen communities are very small and are dominated by generalist species, questioning their potential roles as drivers of plant diversity in these Amazonian forests.

Key Words: Biodiversity, Neotropical forests, Janzen-Connell, host specialization

\section{Introduction}

Neotropical forests are major diversity hotspots for plants (Jablonski et al., 2006; Antonelli \& Sanmartin, 2011; Ter Steege et al., 2013). Amongst the multiple hypotheses proposed to explain how plant species coexistence is promoted in these especially diverse 
forests (Wright, 2002), environmental filtering and negative density dependence of hostspecific natural enemies have been highlighted (John et al., 2007, Mangan et al., 2010, Philipson et al., 2012; Bever et al., 2015). Indeed, the role of pathogens in the maintenance and structure of plant diversity has been a major topic in community ecology (Alexander, 2010; Keesing et al., 2010), especially in Neotropical forests (Mangan et al., 2010; Terborgh, 2012; Bagchi et al., 2014). The Janzen-Connell hypothesis could explain the maintenance of plant diversity by an accumulation of host-specific natural enemies near reproductive adults that affects their offspring in the vicinity, thus limiting host plant species abundance and aggregation (Janzen, 1970; Schupp, 1992; Mills, 1998). This hypothesis requires that natural enemies have a significant degree of host specialization, even if they do not have to be strict species-level specialists (Bagchi et al., 2014; Bever et al., 2015). Alternatively, pathogens may be generalists and structured more by environmental filtering and biogeographic history than by host plant community structure (Bever et al., 2015).

Because the genus Phytophthora contains important plant pathogen species, often Phytophthora species are often involved in seedling mortality, with a worldwide presence and an important economic impact (Hansen, 2015). These pathogens could represent a good target to study Janzen-Connell effects and host specialization in Neotropical forests. Indeed, Phytophthora species exhibit a large diversity of aggressiveness and host range (Erwin and Ribeiro, 1996). By 2018, the genus encompassed 173 described species and eight hybrids, with an estimation of 326 total species (Scott et al., 2018), divided in twelve phylogenetic clades, corresponding to aquatic opportunists, foliar pathogens, or soil-borne pathogens (Hansen, 2015). However, Phytophthora communities have been understudied in Neotropical forests.

The few studies on Phytophthora in tropical forests have focused on characterizing Phytophthora diversity, without explicit focus on the factors shaping these communities. For example, Zeng et al., 2009, found 14 species in the tropical island of Hainan, sampled from plant materials, soils or water at five locations, although only five species were found in forest. In their study across Australia, Burgess et al., 2019, sampled 20 locations in the subtropical/tropical Queensland and found 13 Phytophthora species, among which the most frequent were $P$. cinnamomi and $P$. heveae. Wallace, 2015, showed that Phytophthora diversity could be relatively high in Neotropical forests of Costa Rica, with 21 species found in various forest locations. Some species such as $P$. cinnamomi, $P$. heveae, $P$. castaneae were common across these studies and appear to be widespread in tropical forests (Zeng et al., 2009, Wallace, 2015, Burgess et al., 2017, Jung et al., 2017).

A traditional method for the study of soil-borne Phytophthora communities is the baiting technique. This approach involves use of plant tissues, usually leaves, as baits on which the targeted pathogens produce characteristic lesions. Isolation onto selective agar medium from the lesions enables detection and determination of species using molecular barcodes. More recently, high-throughput sequencing (HTS) methods were applied to study Phytophthora communities (Vettraino et al., 2012; Coince et al., 2013; Català et al., 2015; Burgess et al., 2017, Català et al., 2017; Bose et al., 2018). With this approach, DNA is directly extracted from environmental samples (e.g. soil), then DNA barcodes are amplified with Phytophthora-specific primers and sequenced for analysis (Scibetta et al., 2012). These methods are less timeconsuming and show greater sensitivity (Shokralla et al., 2012), potentially circumventing biases such as seasonal variation of Phytophthora biomass or activity, and possible specificity of the leaves used as bait toward some Phytophthora species (Tsao \& Ocaña, 1969). Several studies have compared these two approaches, (Vannini et al., 2013; Català, 2017; Bose et al., 2018; Khaliq et al., 2018). The HTS approach generally enables detection of a much higher number of Phytophthora taxa. For example, in Bose et al., 2018, five taxa were detected by baiting whereas 32 taxa were detected by metabarcoding.

In this study, we sampled soil at the stem collar of individuals from tree species belonging to ten different taxonomic families in each of three soil conditions at two different locations in French Guiana. We used baiting/isolation and metabarcoding methods to describe 
Phytophthora communities in these different environments. Our aims were (1) to compare the methods (2) to estimate the diversity of these communities and compare it to diversity of other tropical and temperate studies, and (3) to unravel the primary factors that structure Phytophthora communities in the soils of these Neotropical forest sites. We hypothesized (i) that soil metabarcoding will provide greater precision in community estimates than traditional baiting techniques, (ii) that Phytophthora richness will be similar to other sampled moist tropical forests, higher than that found in temperate forests, and (iii) that host plant identity will play a stronger role than environmental filtering in structuring Phytophthora communities.

\section{Results}

\section{Phytophthora diversity uncovered by baiting \& isolation}

Out of the 93 soil samples, 89 produced lesion spots on Rhododendron leaves, 92 on Avocado leaves and 91 on Cassava leaves. From these 272 bait leaves, 581 isolates were obtained from infection spots, out of which 366 were identified as Phytophthora species (Fig. 2). Among these Phytophthora isolates, 136 were found in TF soils, 128 in SF soils and 102 in WS soils. Phytophthora retrieval success depended on the bait and location (both $p<0.001$ ), but not on the environment $(P=0.83)$ or host family $(P=0.42)$. Fifty out of the 55 samples $(91 \%)$ from the CSG site produced isolates that were identified as Phytophthora through Sanger sequencing, while only 24 out of the 38 samples (63\%) from the Laussat site produced isolates. Phytophthora strain recovery was high on Rhododendron leaves (167 isolates) and Avocado leaves (127 isolates), but lower on Cassava leaves (72 isolates).

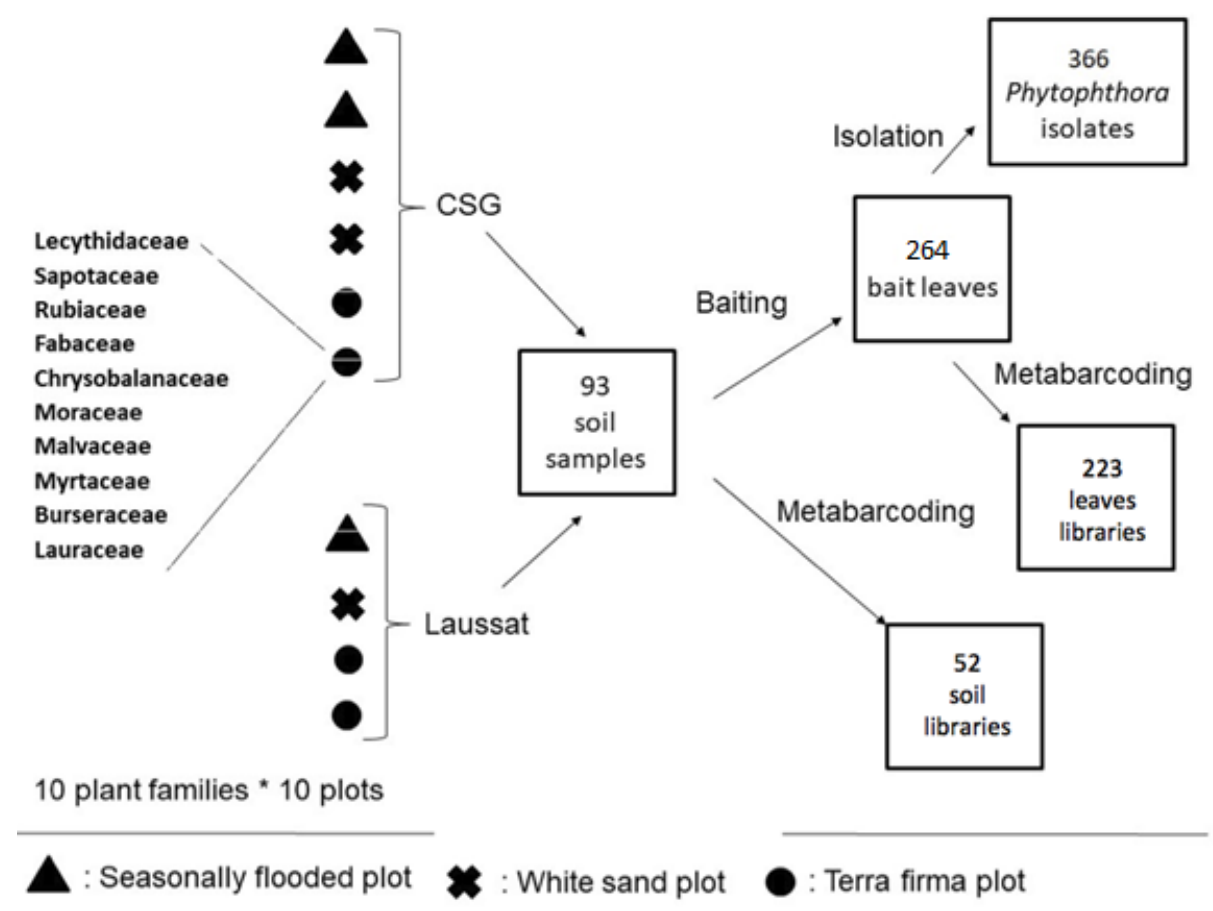

Figure 2. Experiment design with the number of samples at each step, from the sampling to the metabarcoding or isolation. Among 100 potential "tree families x plots" combinations, 93 individuals were sampled because some plant families could not be found in all plots. 
The number of lesions per leaf weight was quantified on Rhododendron bait leaves as a measure of the presence of live Phytophthora in the baited soils. The number of lesions per leaf weight was not related to the location nor to the environment (Fig. 3). However, the number of spots was significantly different between host plant families with a strong "family $x$ environment" interaction (both $p<0.001$ ). Figure 3 shows that while many families had higher lesion number on TF environments compared to WS or SF, other families (Malvaceae, Moreceae, Myrtaceae) showed limited differences between the environments.

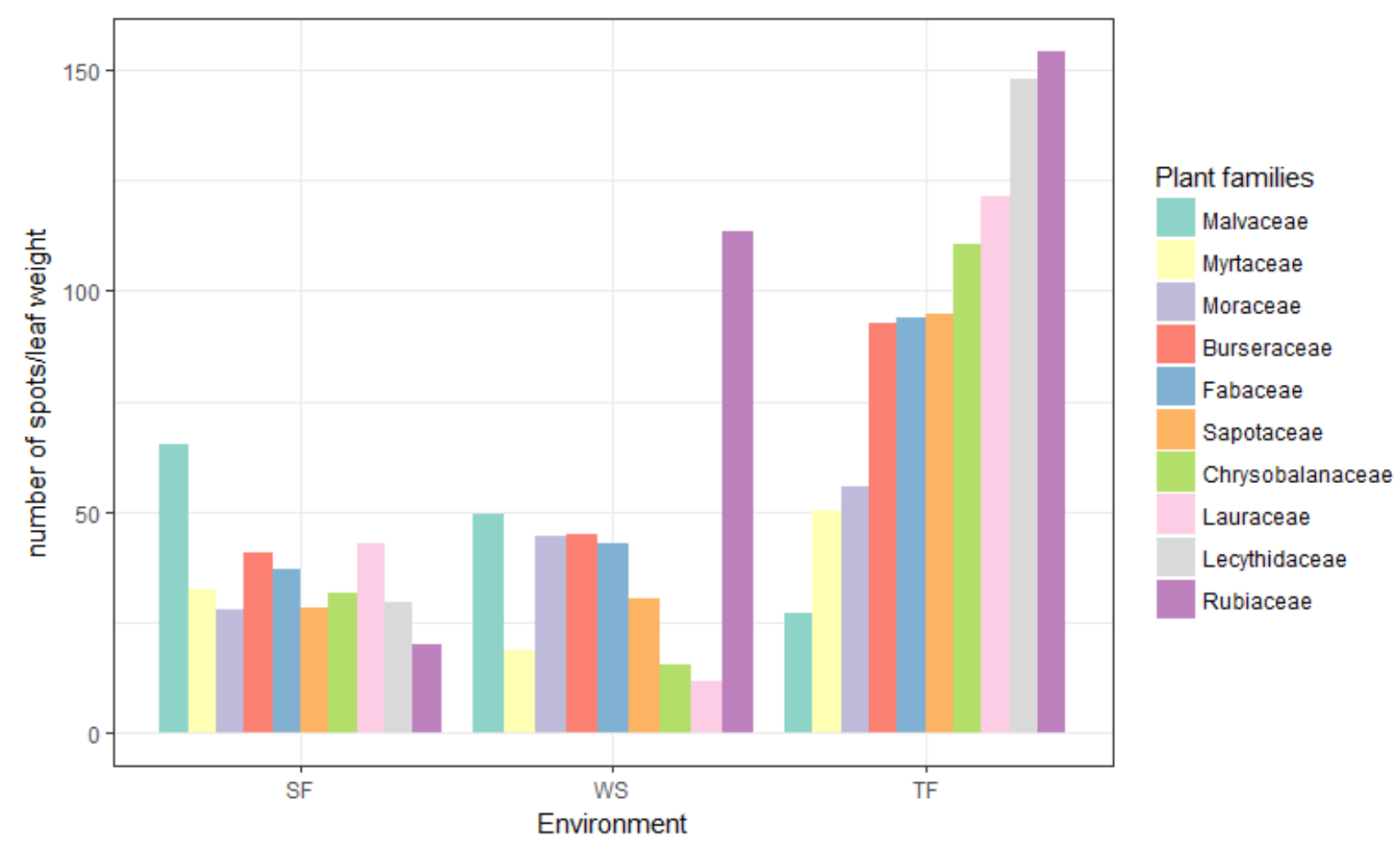

Figure 3. Number of Phytophthora infection spots on Rhododendron leaves per leaf weight. Three forest environments have been studied: TF (terra firma), SF (seasonally flooded), WS (white sand).

Sanger sequences of the ITS region of the Phytophthora isolates were approximately $800 \mathrm{bp}$ in length (min $616 \mathrm{bp}$ - max $876 \mathrm{bp}$ ), versus from 373 to $382 \mathrm{bp}$ for RAS-YPT gene. Sequencing of the ITS region enabled us to identify five potential species: a species close to $P$. heveae (named here $P$. heveae-like, 304 isolates), a species close to $P$. castaneae (named here $P$. castaneae-like, 24 isolates), $P$. cinnamomi (23 isolates), $P$. sp. cuyabensis (6 isolates) and an undescribed species from clade 9, P. sp. neb_1543 (9 isolates). Isolates identified as $P$. heveaelike, $P$. castaneae-like and $P$. sp. cuyabensis showed some heterogeneity of ITS sequences, differing for up to 9 bases between $P$. castaneae-like isolates, up to 4 bases between $P$. heveae-like isolates and 2 bases between $P$. sp. cuyabensis isolates. ITS sequence alignments within either $P$. cinnamomi isolates or $P$. sp. neb_1543 isolates showed $100 \%$ homology. Clustering patterns and assignation from RAS-Ypt and ITS sequences were similar, although variability between RAS-Ypt sequences was lower (up to 3 bases between $P$. heveae-like isolates, up to 2 bases between $P$. castaneae-like isolates, and no variability among isolates of other species). Three plant species used as bait leaves enabled us to retrieve very similar Phytophthora communities, with one exception - P. sp. cuyabensis, the least frequent species, was not recovered from Cassava leaves. 
Six $P$. cinnamomi isolates that were selected randomly among the 23 retrieved isolates, produced oospores after crossing with $P$. cinnamomi mating type $A 1$, and none after crossing with mating type $A 2$, suggesting that their mating type corresponded to A2.

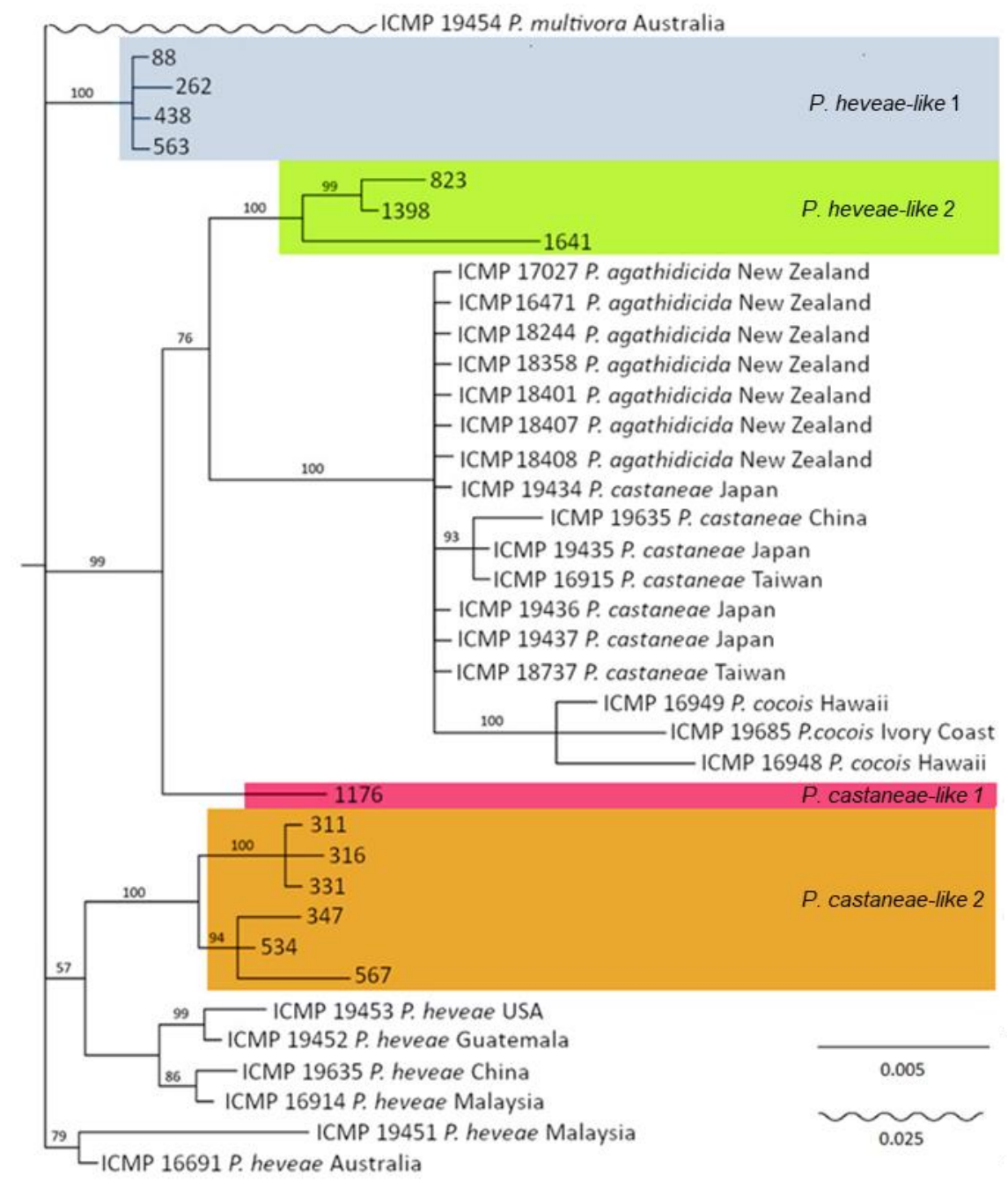

Figure 4: Bayesian inference phylogenetic trees of $14 P$. castaneae-like and $P$. heveae-like isolates created by concatenation of nuclear genetic markers (ITS, RAS-Ypt, Enolase). Reference isolates taken from NCBI are designated by their accession numbers and origins in Table S1. Isolates from this study are designated by either $P$. heveae-like or $P$. castaneae-like. Monophyletic groups of isolates were clustered as groups which were used for further analysis. Distances are given in number of substitutions/site.

\section{Phylogenetic analysis of isolates}

Figure 4 shows the phylogenetic tree built from the three nuclear markers (ITS, RAS$Y p t$, Enolase), either sequenced from the studied set of clade-5 isolates or retrieved from GenBank (Table S1). The isolates retrieved from our study clustered into four separate groups. Two of them were close to $P$. heveae, and the two others were phylogenetically close to $P$. castaneae. Bayesian inference of these Phytophthora strains from nuclear data revealed that distance between respectively the two $P$. heveae-like groups and the two $P$. castaneae-like groups from French Guiana were equal or greater than between reference isolates from different species of clade-5: $P$. castaneae, $P$. cocois, $P$. agathidicida and $P$. heveae (Fig. 4). Thus, these clade- 5 isolates of Phytophthora could potentially belong to new species and were treated as such for the rest of this study. These four Phytophthora groups from clade- 5 could 
be separated based on the ITS sequence alone, although the Enolase sequence was more discriminant. This enabled us to attribute each of the $304 P$. heveae-like and $24 P$. castaneaelike isolates retrieved from the baiting/isolation method to one of the 4 groups. On the other hand, for mitochondrial markers, all 15 isolates from clade- 5 clustered with the reference $P$. heveae (Fig. S1); the mitochondrial phylogeny of the clade-5 isolates was thus not congruent with their nuclear phylogeny. While the two $P$. heveae-like groups could still be separated based on their mitochondrial markers, the two $P$. castaneae-like groups were merged with one of the $P$. heveae-like group.

The four $P$. cinnamomi isolates studied did not exhibit polymorphism for any of the studied markers.

Table 1: List of main Phytophthora species identified from environmental samples with the three methods, with the proportion (\%) of samples containing each species.

\begin{tabular}{lcccc}
\hline \multicolumn{1}{c}{ Species } & Clade & \multicolumn{3}{c}{$\begin{array}{c}\text { Method (\% of samples } \\
\text { containing the species) }\end{array}$} \\
\hline & & Soil metabarcoding & Bait leaves metabarcoding & Isolation \\
\cline { 2 - 5 } P. heveae-like & 5 & 100 & 100 & 92 \\
$P$. castaneae-like & 5 & 8 & 5 & 19 \\
P. cinnamomi & 7 & 11 & 20 & 18 \\
$P$. sp. cuyabensis & 9 & 0 & 0 & 3 \\
P. sp.neb_1543 & 9 & 0 & 3 & 3 \\
P. sp. nov 10 & 10 & 4 & 0 & 0 \\
\hline
\end{tabular}

\section{Metabarcoding approach and comparison with baiting/isolation}

The mean read number per sample was $618 \pm 244$ for direct metabarcoding from soil samples, and $805 \pm 146$ for leaf samples. The samples covering less than 72 reads were discarded. Indeed, a minimum depth of 72 reads was the compromise that allowed keeping most soil samples, while still describing all species of Phytophthora retrieved in the communities. Consequently, 52 soil sample libraries and 223 bait leaves libraries were used in the analysis. Both sets of data gave a mean proportion of $1 \%$ non-Phytophthora reads. Phytophthora reads from these samples were clustered in OTUs with a $99 \%$ similarity threshold, corresponding to five Phytophthora species only (Table 1). The R2 read length was around 400 nucleotides long in the metabarcoding libraries, while the Sanger ITS sequences previously discussed were c. 800 nucleotides long. As a consequence, ITS polymorphism of these shorter ITS fragments did not allow separation of the two $P$. castaneae-like groups, nor the two $P$. heveae-like groups, as could be done with the baiting/isolation results. Among the species retrieved, the $P$. heveae complex ( $P$. heveae and/or the $P$. heveae-like groups) was present in every single sample and represented an average of $97 \%$ of the Phytophthora reads. Other detected species were $P$. cinnamomi, the $P$. castaneae complex, Phytophtora. sp. neb_1543 and a new putative species from clade 10, Phytophthora sp. nov 10.

The species communities obtained with the metabarcoding method differed from the one retrieved with baiting/isolation methods by one species only found by metabarcoding (Phytophthora sp. nov 10) and by one species only found by baiting/isolation ( $P$. sp. cuyabensis). As a result, there was a significant difference in the qualitative composition of communities retrieved with each of the three methods previously described $(p=0.001)$, with the baiting / isolation method showing a lower frequency of the $P$. heveae complex and an increase in the rare species frequency (Table 1). There was no significant difference in the recovered Phytophthora communities between the bait leaf species (Rhododendron, Cassava, Avocado) $(\mathrm{p}=0.9)$. 

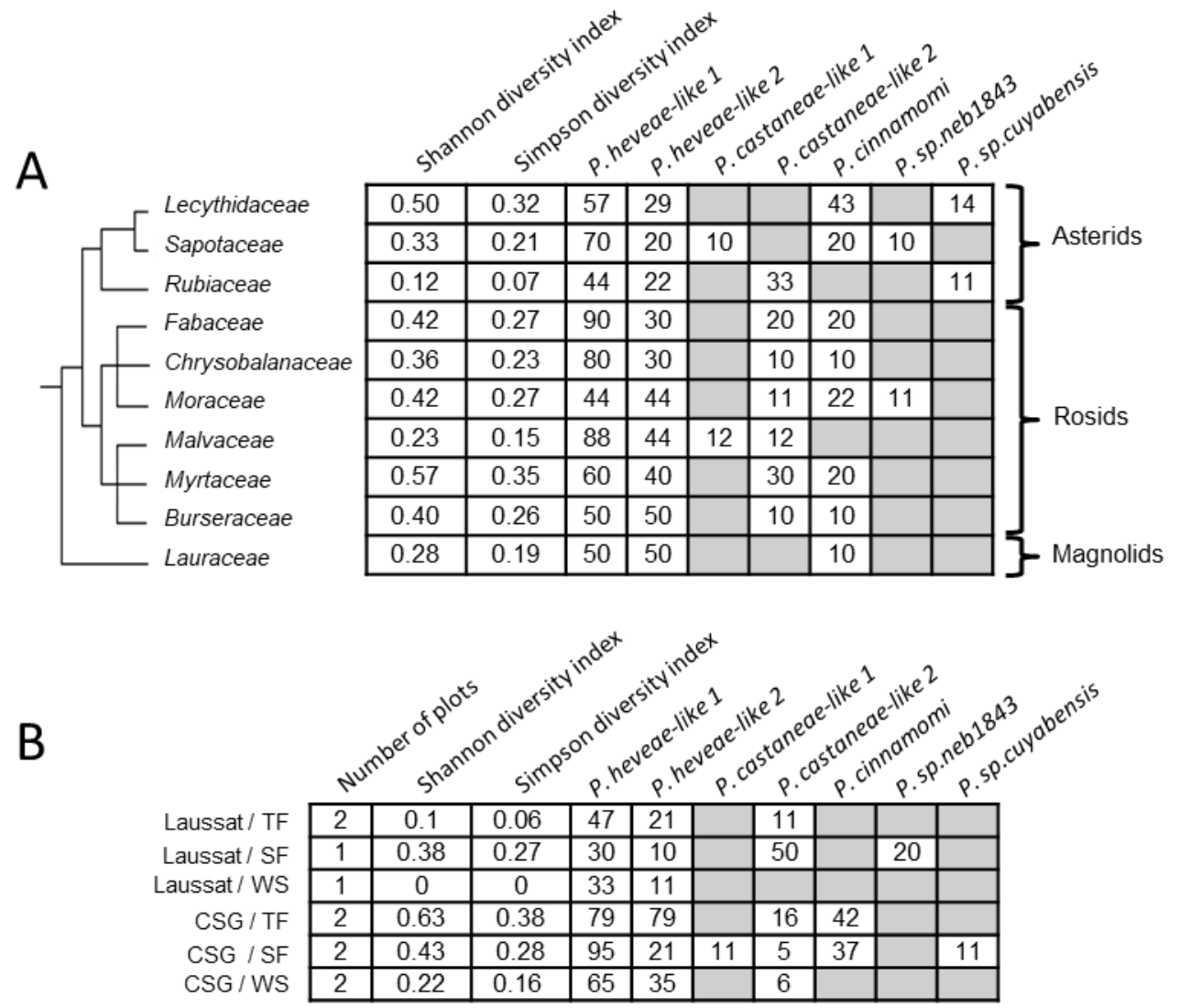

Figure 5. Proportion (\%) of samples in which each of the Phytophthora taxa was retrieved by the baiting / isolation method, for $(A)$ the ten sampled plant families and $(B)$ the three environment types at both locations. One sample can contain several Phytophthora taxa. A: A significant difference was detected between families $(p=0.004)$ but not between higher clades $(p=0.166)$. B: There was a significant difference between the two locations Laussat and CSG $(p=0.001)$ and between environment types $(p=0.017)$. TF=Terra firma. $S F=$ seasonally flooded. WS = white sand.

\section{Community structure analysis}

The average number of species per plot was 1.4, with a dominance of the $P$. heveae complex as mentioned above. Taking into account the four new putative clade- 5 species in the analysis of the Phytophthora communities described by the baiting and isolation method, we showed a strong location (CSG vs Laussat) effect $(\mathrm{p}=0.001)$. Furthermore, a significant effect of forest environment (TF, SF and WS) $(p=0.017)$ was also detected (Fig. 5). The Shannon and Simpson diversity indices were higher in CSG than in Laussat and were higher in SF and TF environments compared to WS (Fig. 5) .A significant effect of host plant family was detected $(p=0.004)$, with an interaction between the family and the location $(p=0.029)$. These results were congruent with analyses of Bray-Curtis similarity indices computed between communities (Table S2). Indeed, these similarity indices computed between the two locations (CSG vs Laussat) were low (0.31), while they were above 0.83 between environments. In addition, the Shannon and Simpson indices showed important variation between plant families (Fig. 5). However, at higher clade levels (Fig. 5A), no effect was detected between Asterids, Rosids and Magnoliids ( $p=0.166)$.

To compare baiting/isolation results with metabarcoding results, we had to merge the two $P$. heveae-like species as well as the two $P$. castaneae-like species, as they could not be distinguished in the metabarcoding data. Combining the two approaches, no environment type effect was detected $(p=0.165)$. An effect of the host trees taxonomy was still detected at the 
family level ( $p=0.017)$, with an interaction with the method used $(p=0.014)$ (Fig. 6). A significant location effect between CSG and Laussat was detected with all methods ( $p=0.001)$, with a strong interaction with the method used $(p=0.002)$.

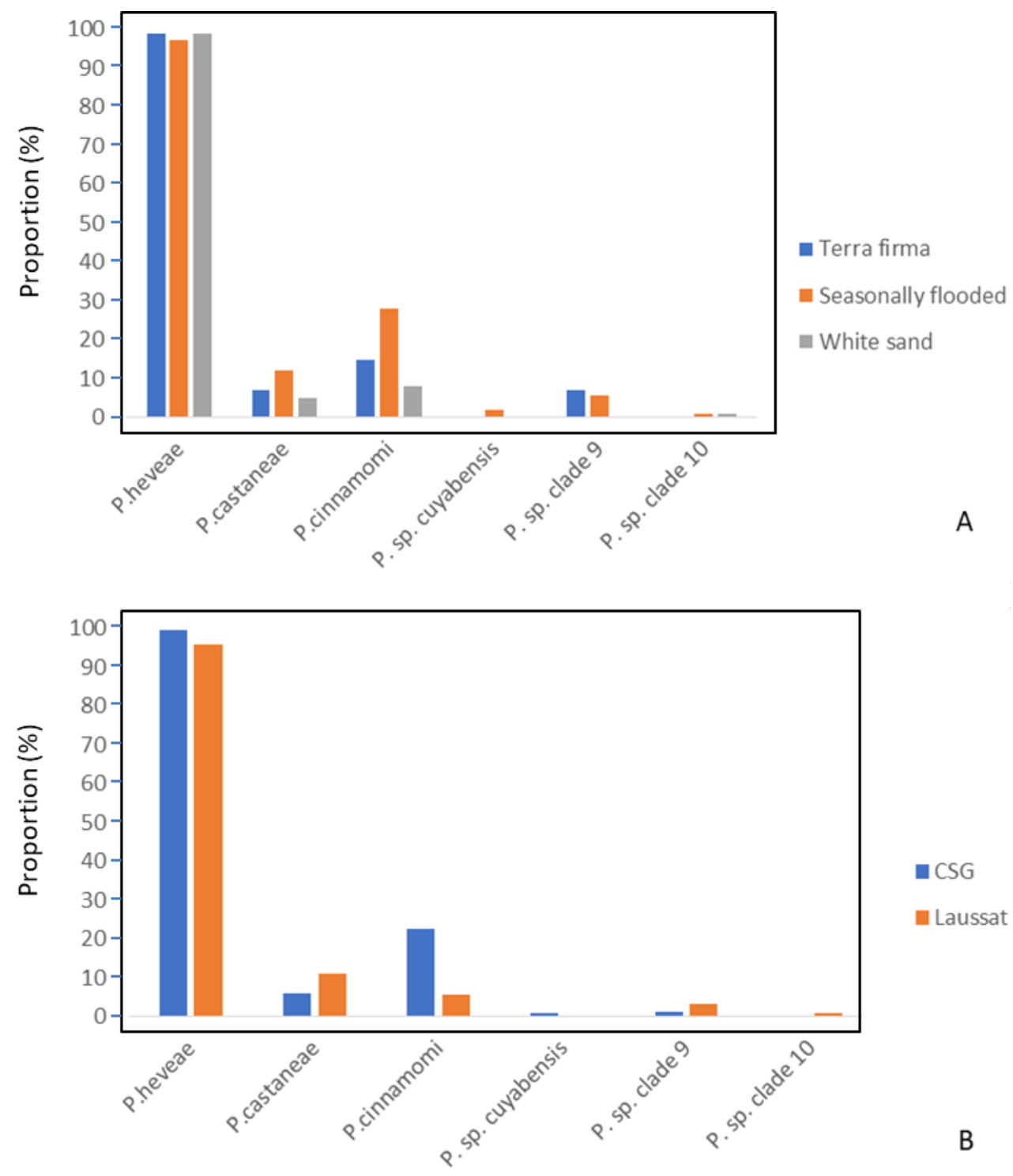

Figure 6. Proportion of samples containing the observed species of Phytophthora, grouped by environment type (A) and location (B). A: Significant difference between the different environment types was detected $(p=0.003)$, with seasonally flooded soils containing more rare species. B: Significant difference between the two locations was detected $(p=0.001)$.

\section{Discussion}

Although the observed Phytophthora community structure depended on the approaches used, our results validated the benefits of HTS for large-scale surveys. Both HTS and baiting approaches uncovered a surprisingly low diversity of Phytophthora in the soils of these two French Guiana locations, with only six species retrieved and a strong dominance of the $P$. heveae complex in all samples. Moreover, no host specialist Phytophthora species were 
identified. Despite this low diversity, the communities were to some degree structured by the plant hosts with a significant family effect, suggesting a certain degree of host preference.

\section{Comparison between baiting/isolation and metabarcoding}

Baiting and molecular approaches have been described as complementary (Català et al., 2015). Baiting techniques are time-consuming, and they may not detect low inoculum. Conversely, metabarcoding methods allow fast and massive pathogen detection. In our study, similar patterns were uncovered by the three approaches. Indeed, the three most abundant species were retrieved with all methods, and taxa of the $P$. heveae complex were largely dominant. However, the use of bait leaves followed by isolation increased the proportion of rare species compared to simple metabarcoding from soil or bait leaves. The isolate morphological observations in the initial step of the baiting/isolation method probably biased the selection toward rare species. Indeed, baiting could be advantageous to investigate communities from larger soil samples $(200 \mathrm{ml}$ versus about $0.5 \mathrm{ml})$. However, it did not enable us to detect additional diversity; rather, it proved to be a time-consuming additional step with little use in the metabarcoding approach. Our results therefore contrast with previous work in which metabarcoding methods were more efficient to describe Phytophthora community structure (Vannini et al. 2013; Català, 2017; Bose et al., 2018; Khaliq et al., 2018.). The suitability of the baiting/isolation method appears to depend largely on the Phytophthora community sampled, on sampling conditions, and on environmental factors. Indeed, baiting can be dependent on time of sampling, quantity and type of inoculum in the soil, species and size of the bait leaves, as well as soil parameters and origins. Timing of the sampling might for example explain the difference in Phytophthora recovery between the two sites we studied, which were sampled almost two months apart. One shortcoming of the metabarcoding method in this study is its inability to discriminate between the two putative $P$. heveae-like species in addition to the two putative $P$. castaneae-like species, because of the shorter length of the ITS fragment used. The baiting method does enable the isolation of living cultures for further characterisation; nevertheless, the less time-consuming metabarcoding from soil DNA was sufficient to obtain the bulk of the results in our study.

\section{Diversity of French Guiana communities of Phytophthora}

The number of putative Phytophthora species observed in these French Guiana soils is lower than what is found in other forest ecosystems, even though our study sampled broadly across plant species from 10 different families representing the breadth of Angiosperm diversity, and across three very different environments. This result is surprising in one of the major biodiversity hotspots of the world and given the tendency of other organisms, including every studied fungal guild, to increase in diversity at lower latitudes (Tedersoo et al., 2014; Willig et al., 2003). Surveys in temperate, Mediterranean and tropical forests of several world regions have revealed a diversity of Phytophthora of 4-10 species per sampling location (Jung et al., 2000; Balci et al., 2007; Oh et al., 2013; Scanu et al., 2015; Sims et al., 2015; Burgess et al., 2017; Català et al., 2017; Bose et al., 2018; Redondo et al., 2018; Mora-Sala et al. 2019). As an example, Burgess et al., 2017, found a mean of 5 species per sampling location in a wide survey across Australia.

The low Phytophthora diversity we observed in French Guiana could be explained by several factors. First, we investigated two sites both located in the Guyana costal range under similar climatic conditions of moist seasonal forests. Wallace, 2015, found a wider diversity of Phytophthora in Neotropical forests by investigating locations of differing hygrometry and altitude (plain rainforests vs. mountain cloud forests). In the same study, the author suggests that a greater diversity can be found in water streams. Also, in our study, we investigated soil adjacent to non-symptomatic juvenile trees irrespective of their proximity to conspecific adult trees, and host-specific Phytophthora species might not have accumulated on them if they were not adjacent to conspecific adults. Finally, even coastal forests in French Guiana receive 
much less exposure to human disturbance than many other tropical and temperate forests. Many common Phytophthora species have been shown to be invasive and spread through worldwide trade (Santini et al., 2013; Jung et al., 2016), and human occupancy and history of trading could be decisive factors for predicting Phytophthora diversity. Indeed, Phytophthora diversity has been linked to the degree of anthropogenic disturbance (Dale, 2018; Redondo et al., 2018), with the average number of Phytophthora species by location reaching nine in urban environments and only six in natural environments (Dale, 2018). In addition, Ruiz Gomez et al. (2019) find alpha-diversity of soil pathogenic Oomycetes was not correlated to the alphadiversity of plants in Andalusian forests, but it would seem to be more related to the nature of the fungal community present in the soil. This calls for more standardized community descriptions in various parts of the world, especially tropical areas, which would allow future meta-analyses of Phytophthora diversity and composition, perhaps in link with other soil microorganisms communities such as fungi.

Strikingly, the three dominant Phytophthora groups we observed in French Guiana, $P$. heveae, $P$. castaneae and $P$. cinnamomi are also the dominant Phytophthora groups in Hainan and Queensland soils (Zeng et al., 2009; Burgess et al., 2017). This suggests a similarity of the Phytophthora communities in tropical soils from South Asia to Australia and South America. For $P$. heveae and $P$. castaneae, this similarity could be spurious, as we found that they are likely closely related but different species. The low, but recurrent, nucleotide polymorphism of ITS sequences obtained from genotyped strains further suggests a potential species complex. The analysis of additional markers confirms that both putative species are heterogeneous and probably distinct from $P$. heveae and $P$. castaneae. The existence of isolates close but distinct from $P$. heveae and $P$. castaneae have already been reported by Zeng et al., 2009, in Hainan. Clade 5 has therefore recently been revised (Weir et al., 2015). However, part of the taxon of this $P$. hevea and $P$. castaneae species complex could be hybrid. Indeed, hybridization has been shown to be a common feature in natural populations of Phytophthora (Burgess et al, 2015). Thus, the discrepancy between the nuclear and mitochondrial markers of the $P$. heveae and $P$. castaneae complexes could be an indicator of hybridization events. In addition, the ambiguity on topology of both phylogenetic trees could possibly be due to an introgressive hybridization of a $P$. heveae-like 2 mitochondrial genome in the two $P$. castaneae-like groups, as mitochondrial genes are inherited as a block during these events (Rubinoff \& Holland 2005, Bachtrog et al. 2006).

P. cinnamomi is considered invasive in more than 70 countries (Erwin \& Ribeiro, 1996), and the six isolates we tested showed 100\% homology in the 6 tested loci. Furthermore, these six randomly selected isolates all belong to only one mating type, which does not suggest a native $P$. cinnamomi population (Erwin \& Ribeiro, 1996). $P$. cinnamomi might therefore be an invasive species in French Guiana, although we cannot confirm this result without testing mating type of all the isolates. This opens the question whether the similarity of Phytophthora communities in the soils of tropical areas is due to cryptic speciation and/or to human-mediated invasions.

\section{Structure of the Phytophthora communities}

The quantity of Phytophthora retrieved on bait leaves showed differences according to forest "environment $x$ host family" interaction, with some families having especially high numbers of lesions on bait leaves in the TF environment. Owing to the large dominance of the $P$. heveae complex, this result probably refers mostly to $P$. heveae-like species. The fact that Oomycete mycelial growth is severely impaired in sandy soils compared to loamy soils (Lumsden, 1981) coupled with studies showing that many Phytophthora do not develop well in low pH soils (Jung et al., 2000) could explain the low quantity in white sand soils for most families. However, it is more surprising that seasonally flooded soils were not more favourable, as high hygrometry is generally favourable to the multiplication of Phytophthora species (Erwin \& Ribeiro, 1996), especially since higher Phytophthora diversity was observed in this environment. The sampling season is probably crucial: the soils were sampled in the two 
studied locations during very wet periods and thus the situation was very favourable also in TF environment. Still, all sampling was achieved in a relatively short timeframe in each location, rendering unlikely any bias between environments induced by the climatic conditions under which samples were collected.

A host plant effect at the family level clearly shaped the composition of Phytophthora community. However, no Phytophthora species were confined to specific families, providing little evidence for host specialization in this forest. Instead, Phytophthora species displayed host preference rather than strict specificity. As illustrated by several studies (Arnold \& Lutzoni 2007; Dickie, 2007; Ishida et al., 2007; Tedersoo et al., 2008; Schimann et al., 2017), fungal communities may be influenced at different taxonomic levels of hosts. However, host taxonomic family effect has been shown to exist for two different fungal ecological groups: tropical epiphytic fungi (Kembel \& Mueller, 2014) and temperate ectomycorrhizal fungi (Tedersoo et al., 2013). Moreover, foliar plant pathogens do exhibit a phylogenetic signal in Neotropical forests (Gilbert \& Webb, 2007).

However, because Phytophthora inoculum (motile zoospores) is known to be disseminated by stream and run-off from ground surfaces, sudden and heavy rainfall in tropical climates may be favourable to a rapid dissemination within both sites studied, therefore homogenising Phytophthora inoculum throughout local forests and blurring host taxonomy effects. Studying fine roots communities, instead of soil communities, could be an alternative method to detect host-specific Phytophthora species. Indeed, Khaliq et al., 2018, retrieved 25 different Phytophthora species on fine roots in urban parks environment, compared to nearly half that amount (13) in soil.

The community we studied is dominated by large host spectrum species such as $P$. heveae-like, $P$. cinnamomi and $P$. castaneae-like. Although initially described in rubber tree plantations in south east Asia, $P$. heveae is mainly a known pathogen of fruits of avocado and cocoa (Turner, 1968; Ochoa-Ascensio, 2011) while $P$. castaneae has been described as infecting chestnut trees (Katsura, 1976). However, in natural environments, they are mostly described as present in soils without causing symptoms to neighbouring trees (Ko et al., 2006; Zeng et al., 2009; Jung et al., 2017). The fact that generalists dominate fungal communities in Neotropical forests has already been described (Ferrer \& Gilbert, 2003; Schimann et al., 2017). Specialists may therefore be represented by very rare species.

Our study revealed that Phytophthora does not appear to be a promising agent of negative density dependence and Janzen-Connell effects in these French Guianan forests. However, only temporal demographic data, including long-term survival analysis of tropical seedlings, will ultimately arbitrate this result (Gilbert et al., 2001). Alternatively, other groups of plant pathogens, such as fungi, could play the prominent role in these forests. We suggest that a general survey of plant pathogens across phyla and in different Neo-tropical forests, would represent an ambitious yet extremely meritorious initiative.

\section{Experimental Procedures}

\section{Sampling and location description}

Soil was sampled in plots located in two regions, in coastal French Guiana, $137 \mathrm{~km}$ apart from each other (Fig. 1), Laussat region $\left(5.48^{\circ} \mathrm{N}, 53.60^{\circ} \mathrm{W}, 4\right.$ plots) in mid-April 2015 and in the "Centre Spatial Guyanais" (abbreviated as CSG, $5.22^{\circ} \mathrm{N}, 52.84^{\circ} \mathrm{W}, 6$ plots) in February and March 2015. These plots belonged to the three main forest environments in French Guyana: white sand (WS, 1 plot in Laussat and 2 in CSG), terra firme (TF, 2 plots in Laussat 2 in CSG), and seasonally flooded forests (SF, 1 plot in Laussat and 2 in CSG). Each plot was $10.000 \mathrm{~m} 2$. These three types of environments are described in Randall, 2017. The sample locations were relatively undisturbed. In each plot, 50 to 60 saplings (2-3 m in height) belonging to ten taxonomic families were selected for sampling (two to twelve individuals per family). The sampled saplings did not present any visible symptoms of disease. The host families were 
Burseraceae, Chrysobalanaceae, Fabaceae, Lauraceae, Lecythidaceae, Malvaceae, Moraceae, Myrtaceae, Rubiaceae and Sapotaceae. Focal families were selected for their relatively large distribution across Amazonian forests within the targeted environment types and the breadth of Angiosperm diversity they represent, as they belong to three major Angiosperms clades: the Asterids, Rosids and Magnoliids (see Fig. 5 for their repartition into these clades). Three soil samples $5-10 \mathrm{~cm}$ deep were collected at $15-40 \mathrm{~cm}$ from the stem collar after removing the litter at the base of each sapling. In each plot, soil samples collected from saplings belonging to the same family were then pooled. As all ten tree families could not be found in all ten plots, the number of pooled soil samples was 93 .

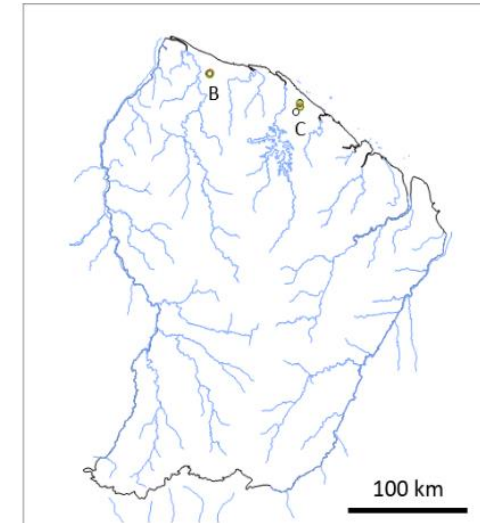

A

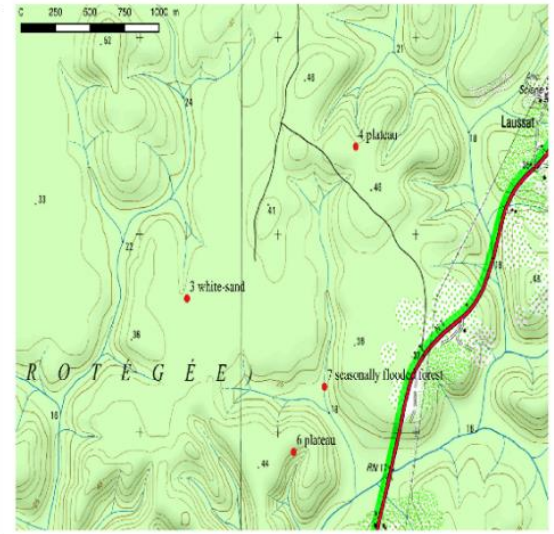

B

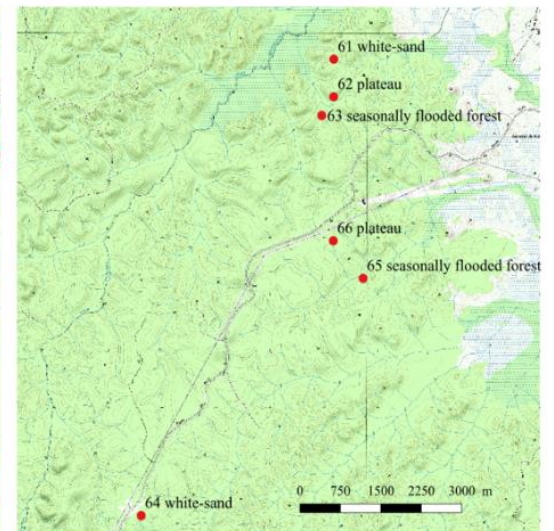

C

Figure 1. Sampling sites of the French Guiana experiment. A: Map of French Guiana showing the locations sampled for this study (B=Laussat; $C=C S G)$. B and $\mathbf{C}$ : Maps of Laussat (left) and CSG (right) showing the sampled plots as red dots. "Plateau" = Terra firma environment.

\section{Baiting and isolation}

For each soil sample, two 1 I plastic containers filled with $200 \mathrm{~mL}$ of homogenised soil submerged by $500 \mathrm{~mL}$ of distilled water were prepared for baiting. In one container, three leaves of Rhododendron 'Cunningham's White' were placed floating upon the water, while the other received one leaf each of Cassava (Manihot esculenta) or Avocado (Persea americana). Care was taken to select flat leaves so to have homogeneous contact between the bait and the water. After three days of incubation at $20-22{ }^{\circ} \mathrm{C}$, bait leaves were collected and weighed. The number of lesions was quantified on Rhododendron leaves only, because lesions became immediately too large and confluent on Cassava and Avocado leaves, preventing accurate quantification of infections. For each combination of bait leaf $x$ soil sample, up to 10 lesions were cut and placed in Petri dishes containing a Phytophthora selective medium (V8 juice agar complemented with $10 \mathrm{mg} \mathrm{L}-1$ pimaricine, $250 \mathrm{mg} \mathrm{L}-1$ ampicilline, $10 \mathrm{mg} \mathrm{L}-1$ rifampicine, 67 $\mathrm{mg} \mathrm{L}-1$ hymexazol, $15 \mathrm{mg} \mathrm{L}-1$ benomyl). After 48 hours incubation in the dark at $25^{\circ} \mathrm{C}$, mycelium was transferred onto new Petri dishes containing the same medium previously described for up to 5 putative Phytophthora distinct colonies per soil sample per bait leaf combination, preferentially selecting isolates with different morphology. After an additional 4872 hours period of incubation, the mycelium was collected for DNA extraction, using the DNeasy 96 Plant kit (Qiagen) according to the manufacturer's instruction. PCR products were amplified from this genomic DNA using the ITS6-ITS4 primer pair targeting the ITS region, using the PCR protocol from Cooke et al. (2000), and the YPh1F-YPh2R primer pair targeting RAS-Ypt gene, using the PCR protocol from Weir et al. (2015). Finally, 366 Phytophthora isolates were sequenced in both directions with the Sanger method. The different steps of the sampling, baiting, isolation and molecular identification process are reported in Fig. 2. 
Additionally, as $P$. cinnamomi is a very important invasive species found worldwide, usually present as only one of the mating types (Erwin \& Ribeiro, 1996), the $P$. cinnamomi isolates retrieved from our samples were further characterized by determining their mating type. They were paired with $\mathrm{A} 1$ and $\mathrm{A} 2$ mating types of $P$. cinnamomi isolates from a reference collection, using the method described by Zentmyer (1979).

\section{Phylogenetic analysis of isolates}

As clade 5 isolates (phylogenetically close to $P$. castaneae and $P$. heveae) were the most frequent in our study, twenty of these isolates were selected for further investigation of their genetic diversity. We selected these isolates to maximize their ITS sequence diversity. We then sequenced for each one the RAS-YPT gene and three additional genetic markers, Cox, Enolase and NADH genes (see (Weir et al. 2015) for the method used). Multiple sequence alignments for each gene were made using Seaview 4.0 (Gouy et al. 2010). Bayesian inference (BI) was used to reconstruct the phylogenies using MrBayes v. 3.2.2 (Ronquist et al. 2012) for the two categories of sequences: first, a concatenation of the mitochondrial markers (Cox and NADH), and secondly another concatenation of the nuclear markers (ITS, RAS-Ypt and Enolase). Nuclear genes showed congruent phylogenies, and so did mitochondrial genes. However, the phylogenies were not congruent between nuclear and mitochondrial genes, so we did not create a tree based on all five genes. Sequences of clade5 Phytophthora from Weir et al. were used as references, and in both trees, $P$. multivora was used as outgroup. Two P. cinnamomi isolates (clade-7) from Laussat and two from CSG were also randomly selected and sequenced for the same markers.

\section{Metabarcoding and Illumina Miseq sequencing}

As detailed in Figure 1, two sets of DNA samples were created by extracting DNA from either (1) the 93 soil samples or (2) the 264 bait leaves corresponding to the three different bait species (Rhododendron, Avocado and Cassava, i.e. $93 \times 3$ bait leaves, minus 15 leaves showing no infection and discarded for further analysis). Soil samples were air-dried and sieved ( $2 \mathrm{~mm}$ mesh size). DNA extraction was performed using MP Biomedical Fast DNA ${ }^{\mathrm{TM}}$ SPIN Kit for soil on $500 \mathrm{mg}$ of dried soil according to the manufacturer's instructions. Bait leaves were dried and ground using liquid nitrogen, and DNA of $500 \mathrm{mg}$ leaf samples was extracted using DNeasy 96 plant kits.

PCR products were amplified from these 357 DNA samples using a nested PCR approach: the primer pair oom18SITS7 was used for the first round and the primer pair 18Ph2F/5.8-1R for the second round. The PCR protocol and the primer sequences are detailed in (Legeay et al., 2019). In order to detect potential contaminants, fifteen control samples, consisting of pure distilled water added to the PCR mix, were included in the same PCR plates. The multiplexing and the Illumina MiSeq sequencing (half-run) were done by the GeT-PlaGe platform of Toulouse (http://get.genotoul.fr/).

\section{Bioinformatics analysis}

Sequences were sorted and trimmed according to their quality using Mothur (Schloss et al., 2009) and Usearch (Edgar, 2010). Unfortunately, the quality of $R 1$ and $R 2$ reads was medium and the depth of sequencing was very heterogeneous between the samples. The R2 reads were finally retained because they covered the ITS1 nucleotide polymorphism region. The reads were then dereplicated to remove duplicated sequences and sorted by decreasing abundance, and the singletons were discarded using the sortbysize command of Usearch. Sequences were then clustered together to make consensus mOTUs with $99 \%$ similarity threshold, using cluster_otus command of Usearch. Generated mOTUs were taxonomically assigned using the BLAST algorithm against a database extracted from the NCBI database, containing all sequences assigned to Oomycetes with the "ITS "and "Internal Transcribed 
Spacer" keywords in their definitions. OTUs assigned to the same species were merged according to their taxonomic identity at the species level. Given the heterogeneity of the sequencing depth, we defined a compromise between the maximum number of samples and the minimum number of reads in each sample to cover the optimal diversity of Phytophthora. In addition, because the Sanger sampling has much less depth than metabarcoding, and because Phytophthora diversity is known to be relatively low, we chose to submit the metabarcoding library to processes of decreasing random subsampling. As illustrated in Figure S2, we could have kept only a hundred samples $(n=120)$ with a sequencing depth $>1000$ reads (Fig. S2, insert D). However, compared to Sanger sequencing data, this depth of sequencing does not allow the identification of additional Phytophthora species. Consecutively, we chose to normalize the samples by subsampling 72 reads because this was the number of reads which maximized the quantity of rare species retrieved in all samples (Fig. S2, insert B). Indeed, this Phytophthora diversity was identical to that observed with 1000 reads per sample from 120 samples. Due to quantitative distortions using these amplification and sequencing methods (Legeay et al., 2019), sequencing results were only analyzed qualitatively (i.e. presence or absence of species). ITS sequences were deposited in GenBank under the accession numbers MH938206 - MH938223. The sequences of RAS-Ypt, Enolase, Cox and NADH regions are available in the DRYAD database (http://datadryad.org/). DRYAD entry doi:XXXXX. The Miseq raw data were deposited in the Sequence Read Archive (http://www.ncbi.nlm nih.gov/sra) as SUB5066167 (temporary access number).

\section{Data analysis}

The efficiency of isolation from baits was studied by analysing the likelihood that a retrieved isolate was a Phytophthora species using a mixed logistic regression with a logit link, taking into account the bait leaf species, the environment, the host plant family and the location (glmer function of $\mathrm{R}$ ). The plot was added as a random factor.

The number of lesions per bait leaves was analysed as a surrogate for the quantity of Phytophthora inoculum in soil. Effects of the different factors, host plant family, environment and location, on the number of lesions per bait leaf weight were tested with a generalized linear model using a Poisson distribution and a log link, with the medium leaf weight as offset (glmer function of $\mathrm{R}$ ). The plot was added as a random factor.

Differences in the composition of Phytophthora communities between the different methods, environments, locations and host families were tested by Permutational Multivariate Analysis of Variance (PERMANOVA) using the adonis function (number of permutations = 500 ) in the vegan package of $R$ (Oksanen et al., 2016). As all information on Phytophthora species composition could not be used in the metabarcoding data, in particular on $P$. heveae and $P$. castaneae complexes, a second analysis was performed using only the data from the baiting/isolation study. To further characterize the diversity of communities in the different environment / families, we computed the Shannon diversity index for each host family and each "environment x location" level using diversity function from the vegan package.

\section{Acknowledgements}

We gratefully acknowledge $\mathrm{E}$. Morin for her assistance in bioinformatics advices and $\mathrm{A}$. Gillet for her technical support. JL holds a PhD fellowship awarded by the "Agence Nationale de la Recherche" (ANR) as part of the ANR Blanc program NEBEDIV to CB, MB and HS (ANR13-BSV7-0009) and the "Institut National de la Recherche Agronomique" (Metaprogramme MEM). UMR IAM and this work were also supported by a grant overseen by the French National Research Agency as part of the "Investissements d'Avenir" program (ANR-11-LABX0002-01, Lab of Excellence ARBRE). The UMR EcoFoG is supported by the French National 
Research Agency as part of the "Investissements d'Avenir" program (Lab of Excellence CEBA, ref. ANR- 10- LABX- 25- 01).

\section{References}

Alexander HM (2010) Disease in Natural Plant Populations, Communities, and Ecosystems: Insights into Ecological and Evolutionary Processes. Plant Disease 94:492-503.

Antonelli A, Sanmartin I (2011) Why are there so many plant species in the Neotropics? Taxon 60:403-414

Arnold AE, Lutzoni $F$ (2007) Diversity and host range of foliar fungal endophytes: are tropical leaves biodiversity hotspots? Ecology 88:541-549.

Bachtrog D, Thornton K, Clark A, Andolfatto P (2006) Extensive introgression of mitochondrial DNA relatives to nuclear genes in the Drosophila Yakuba species group. Evolution 60: 292-302

Bagchi R, Gallery RE, Gripenberg S, et al (2014) Pathogens and insect herbivores drive rainforest plant diversity and composition. Nature 506:85-88.

Balci Y, Balci S, Eggers J, et al (2007) Phytophthora spp. Associated with Forest Soils in Eastern and North-Central U.S. Oak Ecosystems. Plant Disease 91:705-710.

Bever JD, Mangan SA, Alexander HM (2015) Maintenance of Plant Species Diversity by Pathogens. Annual Review of Ecology, Evolution, and Systematics 46:305-325.

Bose T, Wingfield MJ, Roux J, Vivas M, Burgess TI (2018) Community composition and distribution of Phytophthora species across adjacent native and non-native forests of South Africa. Fungal Ecology 36: 17-25.

Burgess, TI (2015). Molecular Characterization of Natural Hybrids formed between five Related Indigenous Clade 6 Phytophthora Species. Édité par Mark Gijzen. Plos One 10: e0134225.

Burgess TI, White D, McDougall KM, et al (2017) Distribution and diversity of Phytophthora across Australia. Pacific Conservation Biology 23:150.

Català S (2017) Development of DNA massive sequencing techniques and RealTime PCR for the detection, identification and quantitation of Phytophthora spp. in environmental samples. PhD Thesis, Universitat Politècnica de València.

Català S, Berbegal M, Pérez-Sierra A, Abad-Campos P (2017) Metabarcoding and development of new real-time specific assays reveal Phytophthora species diversity in holm oak forests in eastern Spain. Plant Pathology 66:115-123.

Català S, Pérez-Sierra A, Abad-Campos P (2015) The Use of Genus-Specific Amplicon Pyrosequencing to Assess Phytophthora Species Diversity Using eDNA from Soil and Water in Northern Spain. PLOS ONE 10:e0119311.

Coince A, Caël O, Bach C, et al (2013) Below-ground fine-scale distribution and soil versus fine root detection of fungal and soil oomycete communities in a French beech forest. Fungal Ecology 6:223-235.

Cooke DEL, Drenth A, Duncan JM, et al (2000) A Molecular Phylogeny of Phytophthora and Related Oomycetes. Fungal Genetics and Biology 30:17-32.

Dale A (2018) Using genomic data to understand anthropogenic influences on Oomycete and Phytophthora communities, and the evolution of an alien invasive species responsible for sudden oak death, Phytophthora ramorum. PhD Thesis, University of British Columbia.

Dickie IA (2007) Host preference, niches and fungal diversity. New Phytologist 174:230-233.

Edgar RC (2010) Search and clustering orders of magnitude faster than BLAST. Bioinformatics 26, $2460-2461$.

Erwin DC, Ribeiro OK (1996) Phytophthora Diseases Worldwide. American Phytopathological Society Press, St Paul, MN, pp 269-280.

Ferrer A, Gilbert GS (2003) Effect of tree host species on fungal community composition in a tropical rain forest in Panama: Fungal community composition in Panama. Diversity and Distributions 9:455-468.

Gilbert GS, Harms KE, Hamill DN, Hubbell SP (2001). Effects of seedling size, El Nino drought, seedling density, and distance to nearest conspecific adult on 6-year survival of Ocotea whitei seedlings in Panama. Oecologia, 127: 509-516.

Gilbert GS, Webb CO (2007) Phylogenetic signal in plant pathogen-host range. Proceedings of the National Academy of Sciences 104:4979-4983. 
Gouy M, Guindon S, Gascuel O (2010) SeaView Version 4: A Multiplatform Graphical User Interface for Sequence Alignment and Phylogenetic Tree Building. Molecular Biology and Evolution 27:221-224.

Hansen EM (2015) Phytophthora Species Emerging as Pathogens of Forest Trees. Current Forestry Reports 1:1624

Ishida TA, Nara K, Hogetsu T (2007) Host effects on ectomycorrhizal fungal communities: insight from eight host species in mixed conifer-broadleaf forests. New Phytologist 174:430-440.

Jablonski D, Roy K, Valentine JW (2006) Out of the Tropics: Evolutionary Dynamics of the Latitudinal Diversity Gradient. Science 314:102-106.

Janzen DH (1970) Herbivores and the Number of Tree Species in Tropical Forests. The American Naturalist 104:501-528.

John R, Dalling JW, Harms KE, et al (2007) Soil nutrients influence spatial distributions of tropical tree species. Proceedings of the National Academy of Sciences 104:864-869.

Jung T, Chan, TT, Bakonyi J, Seres, D, Pérez-Sierra A, Yang X, Hong C, Scanu B, Fu CH, Hsueh KL, Maia C, Abad-Campos P, Léon M, Horta-Jung M, 2017. Diversity of Phytophthora species in natural ecosystems of Taiwan and association with disease symptoms. Plant Pathology 66, 194-211.

Jung T, Blaschke H, Osswald W (2000) Involvement of soilborne Phytophthora species in Central European oak decline and the effect of site factors on the disease. Plant Pathology 49:706-718.

Jung T, Orlikowski L, Henricot B, et al (2016) Widespread Phytophthora infestations in European nurseries put forest, semi-natural and horticultural ecosystems at high risk of Phytophthora diseases. Forest Pathology 46:134-163.

Katsura K (1976) Two new species of Phytophthora causing damping-off of cucumber and trunk rot of chestnut. Transaction of Mycological Society of Japan $17: 238-242$

Keesing F, Belden LK, Daszak P, et al (2010) Impacts of biodiversity on the emergence and transmission of infectious diseases. Nature 468:647-652.

Kembel SW, Mueller RC (2014) Plant traits and taxonomy drive host associations in tropical phyllosphere fungal communities. Botany 92:303-311.

Khaliq, I., Hardy, G.E.S.J., White, D., Burgess, T.I., 2018. eDNA from roots: a robust tool for determining Phytophthora communities in natural ecosystems. FEMS Microbiology Ecology 94.

Ko W-H, Wang SY, Ann PJ (2006) The possible origin and relation of Phytophthora katsurae and P. heveae, discovered in a protected natural forest in Taiwan. Botanical Studies 47:5

Legeay J, Husson C, Cordier T, Vacher C, Marcais B, Buée M (2019) Comparison and validation of Oomycetes metabarcoding primers for Phytophthora high throughput sequencing. Journal of Plant Pathology 101: 743748.

Lumsden RD (1981) A Nylon Fabric Technique for Studying the Ecology of Pythium aphanidermatum and Other Fungi in Soil. Phytopathology 71:282.

Mangan SA, Schnitzer SA, Herre EA, Mack KM, Valencia MC, Sanchez EI, Bever JD (2010) Negative plant-soil feedback predicts tree-species relative abundance in a tropical forest. Nature, 466: 752.

Mills KE, Bever JD (1998) Maintenance of diversity within plant communities: soil pathogens as agents of negative feedback. Ecology 79:1595-1601.

Mora-Sala B, Gramaje D, Abad-Campos P, Berbegal M (2019) Diversity of Phytophthora Species Associated with Quercus ilex L. in Three Spanish Regions Evaluated by NGS. Forests 10: 979.

Ochoa-Ascensio S, (2011) Phytophthora heveae causing basal rot of avocado fruit in Mexico, Proceedings VII World Avocado Congress 2011 (Actas VII Congreso Mundial del Aguacate 2011). Cairns, Australia. 5 - 9 September 2011

Oh E, Gryzenhout M, Wingfield BD, et al (2013) Surveys of soil and water reveal a goldmine of Phytophthora diversity in South African natural ecosystems. IMA Fungus 4:123-131.

Oksanen J, Blanchet FG, Kindt R, Legendre P, Minchin P R, O'hara R B, Wagner H (2016) vegan: community ecology package. R package version 2.0-7. 2013. URL http://CRAN. R-project. org/package= vegan.

Philipson CD, Saner P, Marthews TR, et al (2012) Light-based Regeneration Niches: Evidence from 21 Dipterocarp Species using Size-specific RGRs. Biotropica 44:627-636.

Randall WM (2017). A comparison of the forest soils in the Peruvian Amazon: Terra firme, palm, white sand and igap. J Soil Sci Environ Manage. 8(7):130-4. 
Redondo MA, Boberg J, Stenlid J, Oliva J (2018) Functional traits associated with the establishment of introduced Phytophthora spp. in Swedish forests. Journal of Applied Ecology 55:1538-1552.

Ronquist F, Teslenko M, van der Mark P, et al (2012) MrBayes 3.2: Efficient Bayesian Phylogenetic Inference and Model Choice across a Large Model Space. Systematic Biology 61:539-542.

Rubinoff D, Holland BS (2005). Between Two Extremes: Mitochondrial DNA is neither the Panacea nor the Nemesis of Phylogenetic and Taxonomic Inference. Systematic Biology 54: 952-961.

Ruiz Gómez FJ, Navarro-Cerrillo RM, Pérez-de-Luque A, Oßwald W, Vannini A, Morales-Rodríguez C (2019) Assessment of functional and structural changes of soil fungal and oomycete communities in holm oak declined dehesas through metabarcoding analysis. Sci Rep 9: 5315.

Santini A, Ghelardini L, De Pace C, Desprez-Loustau M-L, Capretti P, Chandelier A, Cech T, Chira D, Diamandis S, Gaitniekis T, Hantula J, Holdenrieder O, Jankovsky L, Jung T, Jurc D, Kirisits T, Kunca A, Lygis V, Malecka M, Marcais B, Schmitz S, Schumacher J, Solheim H, Solla A, Szabò, I., Tsopelas, P., Vannini,A., Vettraino, A- M., Webber, J., Woodward, S., Stenlid J (2013) Biogeographical patterns and determinants of invasion by forest pathogens in Europe. New Phytologist197:238-250

Scanu B, Linaldeddu BT, Deidda A, Jung T (2015) Diversity of Phytophthora Species from Declining Mediterranean Maquis Vegetation, including Two New Species, Phytophthora crassamura and $P$. ornamentata sp. nov. PLoS ONE 10, e0143234.

Schimann H, Bach C, Lengelle J, et al (2017) Diversity and Structure of Fungal Communities in Neotropical Rainforest Soils: The Effect of Host Recurrence. Microbial Ecology 73:310-320.

Schloss PD, Westcott SL, Ryabin T, Hall JR, Hartmann M, Hollister EB, Lesniewski RA, Oakley BB, Parks DH, Robinson CJ, Sahl JW, Stres B, Thallinger GG, Van Horn DJ, Weber CF (2009) Introducing mothur: OpenSource, Platform-Independent, Community-Supported Software for Describing and Comparing Microbial Communities. Applied and Environmental Microbiology 75, 7537-7541.

Schupp EW (1992) The Janzen-Connell Model for Tropical Tree Diversity: Population Implications and the Importance of Spatial Scale. The American Naturalist 140:526-530.

Scibetta S, Schena L, Chimento A, Cacciola SO, Cooke DE (2012). A molecular method to assess Phytophthora diversity in environmental samples. Journal of microbiological methods 88: 356-368.

Scott P, Bader MK.-F, Burgess T, Hardy G, Williams N (2019) Global biogeography and invasion risk of the plant pathogen genus Phytophthora. Environmental Science \& Policy 101: 175-182.

Shokralla S, Spall JL, Gibson JF, Hajibabaei M (2012) Next-generation sequencing technologies for environmental DNA research. Molecular Ecology 21:1794-1805.

Sims LL, Sutton W, Reeser P, Hansen EM (2015) The Phytophthora species assemblage and diversity in riparian alder ecosystems of western Oregon, USA. Mycologia 107:889-902.

Tedersoo L, Bahram M, Polme S, et al (2014) Global diversity and geography of soil fungi. Science 346:12566881256688.

Tedersoo L, Jairus T, Horton BM, et al (2008) Strong host preference of ectomycorrhizal fungi in a Tasmanian wet sclerophyll forest as revealed by DNA barcoding and taxon-specific primers. New Phytologist 180:479-490.

Tedersoo L, Mett M, Ishida TA, Bahram M (2013) Phylogenetic relationships among host plants explain differences in fungal species richness and community composition in ectomycorrhizal symbiosis. New Phytologist

ter Steege H, Pitman NCA, Sabatier D, et al (2013) Hyperdominance in the Amazonian Tree Flora. Science 342:1243092-1243092.

Terborgh J (2012) Enemies Maintain Hyperdiverse Tropical Forests. The American Naturalist 179:303-314.

Tsao PH, Ocaña G (1969) Selective Isolation of Species of Phytophthora from Natural Soils on an Improved Antibiotic Medium. Nature 223:636-638.

Turner PD. (1968). Pod rot of cocoa in Malaysia caused by Phytophthora heveae. FAO Plant Protection Bulletin 16: 33-34.

Vannini A, Bruni N, Tomassini A, et al (2013) Pyrosequencing of environmental soil samples reveals biodiversity of the Phytophthora resident community in chestnut forests. FEMS Microbiology Ecology 85:433-442.

Vettraino AM, Bonants P, Tomassini A, et al (2012) Pyrosequencing as a tool for the detection of Phytophthora species: error rate and risk of false Molecular Operational Taxonomic Units. Letters in Applied Microbiology 55:390-396.

Wallace SF (2015) Diversity of Phytophthora Species in Costa Rica's Tropical Forest. PhD Thesis, Digital Repository at the University of Maryland. (https://doi.org/10.13016/m2fw79) 
Weir BS, Paderes EP, Anand N, et al (2015) A taxonomic revision of Phytophthora Clade 5 including two new species, Phytophthora agathidicida and P. cocois. Phytotaxa 205:21.

Willig MR, Kaufman DM, Stevens RD (2003) Latitudinal Gradients of Biodiversity: Pattern, Process, Scale, and Synthesis. Annual Review of Ecology, Evolution, and Systematics 34:273-309.

Wright JS (2002) Plant diversity in tropical forests: a review of mechanisms of species coexistence. Oecologia 130:1-14.

Zeng H, Ho H, Zheng F-C (2009) A Survey of Phytophthora Species on Hainan Island of South China. Journal of Phytopathology 157:33-39.

Zentmyer GA (1979). Stimulation of sexual reproduction in the A2 mating type of Phytophthora cinnamomi by a substance in avocado roots. Phytopathology, 69: 1129-1131. 